\title{
What is the Function of the Ultrasonic Therapy Compared with Short-Wave Therapy?
}

\author{
Reprinted from Siemens $S R W-N e w s$ by kind permission of Protea Holdings
}

$\mathbf{O}^{\mathrm{F}}$ recent years, the thermic effect of ultrasonic treatment has been emphasized more and more in the course of the discussions concerning the therapeutic mode of action of ultrasonics; some authors (Bode, Matthes, Patzold, Theismann) even claim that heat is the essential agent of ultrasonic therapy. Considering this situation, it is reasonable to ask whether the use of ultrasonic therapyin so far as it can be considered purely as a thermic therapyis still justified in view of the existence of shortwave therapy. In order to reply to this question, two points have to be considered in detail, namely :-

1. whether the therapeutically effective agent of ultrasonic therapy has a purely thermic character, and

2. in how far various thermic therapies may justifiably exist together.

There is no doubt that, whenever an ultrasonic treatment is applied, part of the sonic energy is transformed into heat in the tissues (although the resulting increases in temperature are often very slight), so that more or less considerable thermic effects are attendant upon every ultrasonic treatment. To this extent, then, the remarks concerning the importance of thermic effects are certainly justified. On the other hand, however, we find certain ultrasonic effects which cannot be explained in terms of thermic action. For instance, the acceleration of osmotic processes should be mentioned here, which has often been observed and which, although certainly aided by increases

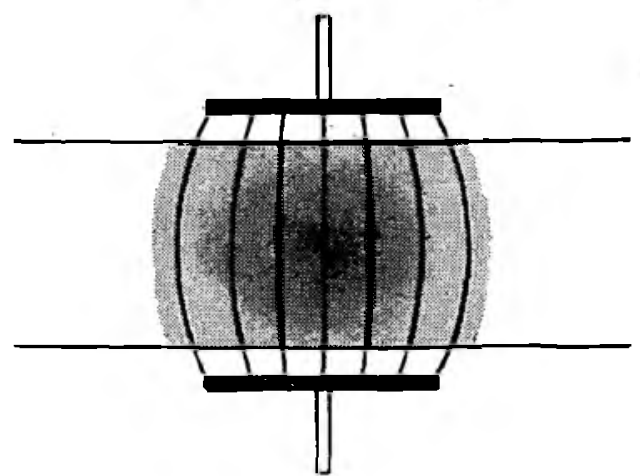

of temperature, is evidently not dependant upon this factor alone, but also on mechanical processes (Barth, Baumgartl, Bruns, Denier, Frenzel, Hinsberg, Hintzelmann, Lehmann, Pohlmann, von Sanden, Schmid, Schultes). In the field of practical therapeutical application it has also been pointed out frequently that the undoubted successes of ultrasonic therapy, for instance in connection with Bechterew's disease, crural ulcers, scleroderma and the healing of wounds, cannot be explained merely in terms of thermic effects. In consequence, the existing material does not justify considering ultrasonic therapy simply as a special form of thermic therapy: direct mechanical action must be taken into account in every case.

If on examination of the first point it appears that the conception of ultrasonic therapy as a pure thermic process is too limited, then it follows that the second point must be reduced to an examination of the therapeutical effects of u]trasonic action as different from other methods of thermic treatment. For this purpose, ultrasonic therapy, short-wave therapy and the application of external heat (heating pads, hot water bottles, hot baths, radiators) will be compared. When such a comparison is established, great differences are observed, both in respect of general and particular characteristics.

Fig. 1 gives a diagrammatic representation of the heat distribution as it generally occurs when a part of the body is under treatment; the short-wave therapy with condenser field always has the character of a "flow" through

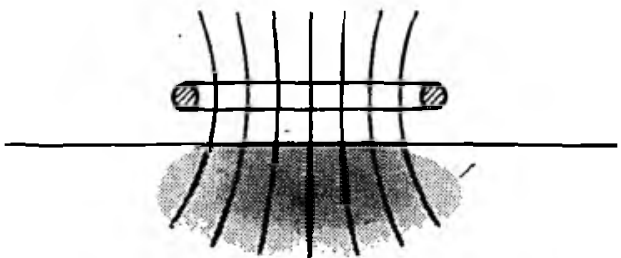

Fig. 1 - Diagrammatic representation of heat distribution in a homogeneous body

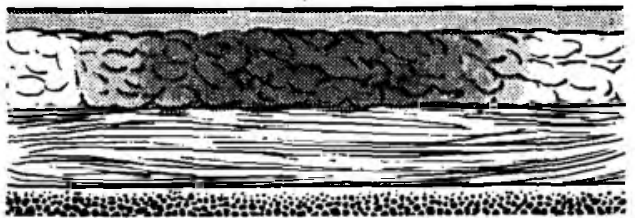

Short-wave therapy with condenser field
Skin

Subcutaneous fatty tissue

Muscles

Bone

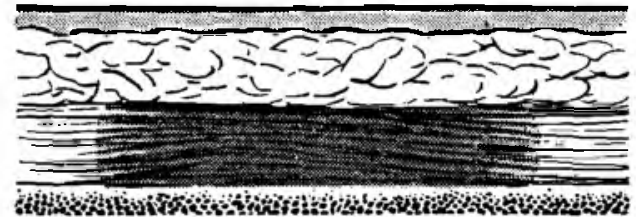

Short-wave therapy with coil field

Fig. 2 - Diagrammatic representation of heat distribution in the tissues 
the whole part of the body; this method makes it possible by selecting a sufficiently large distance between the electrodes and the skin, to concentrate the heat on the inner layers. When a coil field is employed by means of an "induction cable", or of the "drum" which is commonly used in the U.S.A. - the heat production is limited to the layers nearer the surface, but the width of the heated zone is still considerable. Ultrasonic therapy, on the other hand, produces quite different conditions. Here heat production arises only within a narrow beam of sound waves (the half-value layer of which is approximately $3 \mathrm{~cm}$ ). When the usual massage method is employed, moreover, the thermic action on individual points is only intermittently effective. Ultrasonic application results therefore in greater localisation. The application of external heat, on the other hand, has an effect only on the uppermost layers of skin, since no deep heat production can be obtained ; already at a depth of 6 to $8 \mathrm{~mm}$, the increase in temperature is merely $2^{\circ}$ to $3^{\circ}$ centigrades, even when the application is continued for a considerable period of time employing, for instance, a compress at a temperature of $50^{\circ}$ centigrade (Rein). Due to the resulting increase of blood circulation in the regions which lie near the surface, the heat which is being applied is removed from the point of application. In the other two methods, however, this process of heat production and removal also reaches the deep layers to a great extent.

If we consider the heat distribution in different types of biological tissue, we shall also find that definite differences occur (see diagram in Fig. 2).

When the condenser field method is employed in short-wave therapy, the highest absorption of electric

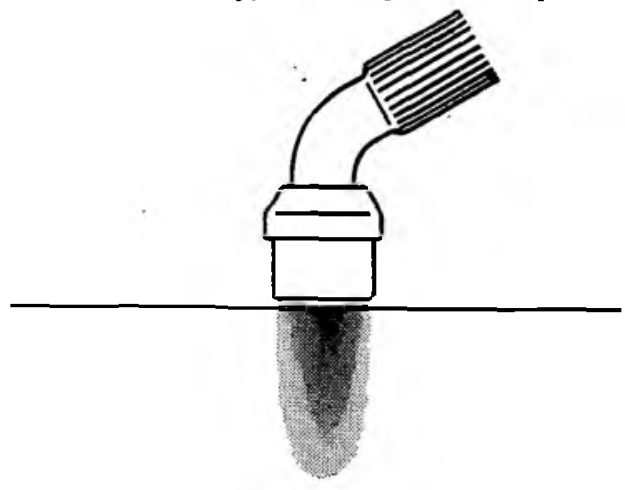

energy and, consequently, the most intensive heat production occurs, for the usual frequencies, in the subcutaneous fatty tissue. When the coil field method is applied, on the other hand, it is the muscle layers which lie near the surface which receive the highest thermic action, because the coil field is a magnetic field, and heat production is the result of eddy currents in these parts of the tissues which are good conductors. The conditions in respect of ultrasonic therapy are again quite different; here it has been found that the thermic action is most considerable near the boundary layers, and we have therefore zones of maximum heat production at the boundary between the subcutaneous fatty layers and the muscle tissues, as well as at the periosteum. The application of external heat, finally, is only effective in the zones nearest the skin, due to the moderate depth of penetration.

Although this summary refers only to some of the most important points in a very general manner, and can therefore certainly not do iustice to various important details, it does however show convincingly that the different methods of thermal application considered are basically different not only in respect of the mode in which the heat is produced, but also-and this is the most decisive point-in the nature of heat distribution in the tissues or parts of the body under treatment. In consequence the reactions of the organism vary according to the method employed.

The question which we are considering here will therefore have to be answered in the sense that ultrasonic therapy is important whenever direct mechanical action is required as an essential therapeutic agent. Several indications have already been mentioned which evidently belong to this category. Insofar as ultrasonic treatment is used mainly for thermal therapy purposes, it will be of specific value in selective heating of boundary layers, such as in the treatment of arthropathy or of inflammatory processes near the surface (e.g. furuncles, sudoriparous abscesses, mastitis, paronychia, etc.). Practising doctors, moreover, emphasize again and again the superiority of ultrasonic therapy in

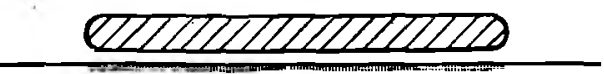

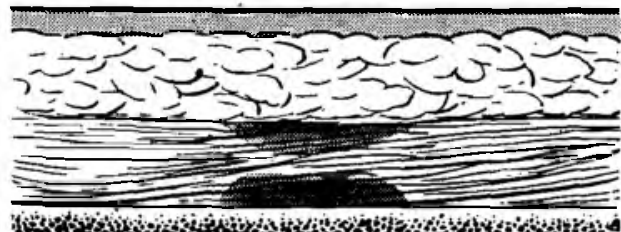

Herot

Ultrasonic therapy
Skin

Subcutaneous fatty tissue

Muscles

Bone

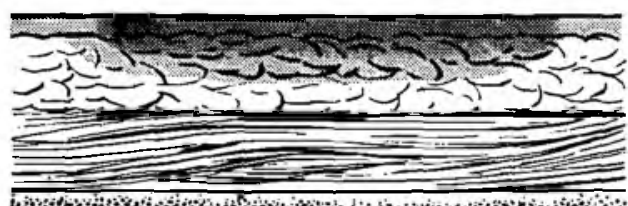

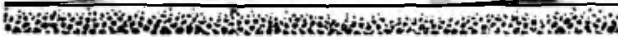

Heat therapy with heating pad 
the treatment of sciatica, neuralgia and neuritis, but the question remains unanswered whether the results are due to mechanical action or to the effect of a specific temperature distribution. The same is true of the well known good results which can be obtained in connection with Bechterew's disease, scleroderma and crural ulcers. Finally, the spasmolytic effect of ultrasonic treatment seems to be superior to that of an exclusively thermal therapy. While the localised action of ultrasonic therapy, however, is limited to peripheral zones (or should, at any rate, be thus limited considering that the deep action of ultrasonic therapy is as yet too little known), deep action is precisely the outstanding characteristic of short-wave therapy. Short-wave treatment is also to be preferred whenever it is desired to have a strong flow of heat through a part of the body, since ultrasonics would result in periosteal pain at a comparatively early stage due to boundary layer heating. From this point of view, then, short-wave therapy can advantageously be used when it is desired to send a flow of heat through the trunk of the body, for instance in diseases of the respiratory tract (such as bronchitis), of the urogenital system (such as adnexitis or prostatitis), of the abdominal organs, etc. Furthermore, diseases in the head (e.g. of the ear, of the paranasal sinus) will always be treated by means of short-wave application.

A detailed discussion of all the important points of view affecting the questions set above would exceed the scope of the present article. The therapeutic "remote effects", for instance, as known in connection with the cutivisceral reflexes in the application of external heat have been completely ignored. Stuhlfauth was probably the first to point to the possibilities of using the vegetativeneural tracts for purposes of ultrasonic therapy, while Loeppen and Schliephake prefer to use the endocrine approach for short-wave stimulation of the hypophysis. It seems that the exploration of the avenues opened up in these fields has just begun. Moreover, combined treatment (for instance by using alternate therapies in the course of a series of sessions) or comprehensive therapy combining short-wave treatment of the whole body (artificial fever) with local ultrasonic treatment (Koeppen) have hardly been tried out up to date. Finally, the definition of the two methods is not to be understood in the sense that each method must be strictly confined to its own indications. In the treatment of neuritis, arthropathy or furuncles, for instance, it will be found that some cases respond better to ultrasonic therapy, while others are more. successfully treated with short-wave therapy.

The short indications contained in the present article may, however, contribute to explain the point of view of those practising doctors who are familiar with the use of ultrasonic therapy, and who believe that-after the excessive use resulting from an ephemeral "fashion" has subsided -ultrasonic therapy, with its well defined field of application, supplements short-wave therapy instead of being its rival. Thus, ultrasonics constitute a valuable addition to the general therapeutic equipment of medical science, and their use in practical medicine is now that new simplified apparatus condensed to the essential details have been introduced, of definite advantage.

Dr. K. v. Sanden

\section{SOUTH AFRICAN RAILWAYS AND HARBOURS SICK FUND}

\section{Appointment of Salaried Physiotherapist-Germiston}

Applications are invited from registered Physiotherapists for appointment to the position of Salaried Physiotherapist, Germiston, at a salary of $£ 600$ per annum, and with the right of private practice.

The salary will be subject to adjustment in accordance with the census of members to be taken on the lst April of each year.

The appointment will be made in terms of the Regulations of the Fund, and will be subject to termination on four months notice being given by either side.

The successful candidate will be required to reside at Germiston, to take up the appointment on a date to be arranged, carry out the duties in accordance with the Regulations of the Fund, and to provide at own expense the necessary rooms, equipment, etc.

Applications should reach the District Secretary, Western Transvaal District Sick Fund Board, Room 342, New Station Buildings, Johannesburbg, not later than 2nd May, 1953, and should state :-

(1) Full name.

(2) Qualifications (when and where obtained).

(3) Experience (when and where obtained).

(4) Date of birth.

(5) Country of Birth.

(6) Whether married or single.

(7) Whether fully bilingual.

(8) Whether South African citizen.

(9) What government appointment, if any, is held.

Canvassing by or on behalf of any applicant is liable to disqualify such applicant.

Any further particulars required may be obtained from the District Secretary, at the above address, on application.

\section{P. J. KLEM,}

General Secretary.

JOHANNESBURG,

April, 1953.

Due to a most unfortunate muddling of the proofs, the article submitted by $\mathrm{Mr}$. David Muskat on "Frozen Shoulder" in the January issue was published with the subject matter in an incorrect sequence. Most sincere apologies are proffered to Mr. Muskat, and it is to be hoped that despite this error, readers were able to follow his most interesting article. 